\title{
Stop Making It Weird 2.0: Imagining a less-weird world
}

\author{
Jolene M. Thibedeau Boyd ${ }^{\mathrm{a}, *}$ and Cassandra J. Beckman ${ }^{\mathrm{b}}$ \\ ${ }^{\text {a }}$ Community Involvement Programs, Minneapolis, MN, USA \\ ${ }^{\mathrm{b}}$ Association for People Supporting EmploymentFirst, Rockville, MD, USA
}

Revised/Accepted November 2018

\begin{abstract}
.
BACKGROUND: The authors continue the dialogue, initiated in 2016, discussing how disability service professionals and society at large can unintentionally create "weird" situations for people with disabilities by creating "special"- that is, segregated-activities and events for people with disabilities, rather than working to include individuals with disabilities in the activities and events that already happen in communities. The authors further explore the continuing trend of calling out and excessively celebrating people's actions and accomplishments based solely on the fact that they experience a disability. This session shares examples of people with disabilities in the news and social media, encouraging discussion about the difference between drawing attention to events that are newsworthy because of their historical context versus those that merely reinforce disability stereotypes.

OBJECTIVE: It is critical to continue challenging disability stereotypes and questioning the value of segregated, disabilityspecific activities that serve to exclude people with disabilities from the community at large, even as they celebrate these "special" opportunities.

CONCLUSION: In this session, a panel of individuals who experience disability shares personal experiences with this kind of "weirdness" and suggest ways to \#stopmakingitweird. The authors provide ideas and discussion to encourage disability professionals, family members of people with disabilities, and people from the community at large to consider their own assumptions and stereotypes while challenging those whom they know and interact with to do the same.
\end{abstract}

Keywords: Segregation, disabilities, disability stereotype, tokenism, inclusion, inspiration porn, newsworthy, special treatment, \#stopmakingitweird

\section{Introduction}

Stop Making It Weird ${ }^{\mathrm{TM}}$ (\#stopmakingitweird) is a campaign that began in 2016 at the APSE National Conference in Cincinnati, $\mathrm{OH}$ with the purpose of drawing attention to the beliefs and actions of disability professionals that unintentionally reinforce disability stereotypes and result in the perpetuation of low expectations and institutionalized segregation of people who experience disability (Davis \& Thibedeau

*Address for correspondence: Jolene Thibedeau Boyd, 5301 Twin Lake Blvd. E., Minneapolis, MN 55429, USA. Tel.: +1 612 910 6180; E-mail: jolenetboyd@gmail.com.
Boyd, 2017). The 2016 conference presentation discussed the insidious nature of excessively celebrating routine, even mundane, achievements of people with disabilities that, for someone without a disability, would simply be accepted as expected behavior. For example, clapping only for a panel presenter who has a visible disability when she finishes her portion of the presentation, but not doing the same for the presenters who do not appear to have a disability (Davis \& Thibedeau Boyd, 2017). Davis and Thibedeau Boyd (2017) maintain that celebrating everyday acts performed by people with disabilities simply because they are performed by people with disabilities may be well-intentioned, but ulti- 
mately suggest that those individuals are less capable. Unfortunately, attitudes such as this create barriers for people with disabilities to experience fullyinclusive lives (Glynn, Perkins Nerlich, \& Accordino, 2018).

\section{Disability as inspiration}

Australian comedian, journalist and disability rights activist, Stella Young, presented a TED (Technology, Entertainment and Design) Talk in Sydney in 2014 where she championed the phrase "inspiration porn" to describe a trend on social media of using images of people with disabilities and captions that objectify people with disabilities for the benefit of those who do not have disabilities. Common inspiration porn memes include photos of individuals, often children, who have obvious disabilities and include captions such as, "The only disability in life is a bad attitude," and, "Your excuse is invalid," (Young, 2014). Memes such as these have been shared and spread extensively across social media platforms, with millions of people viewing and sharing them across the globe.

Some would argue that greater exposure to images and portrayals of individuals with disabilities is beneficial to society at large. But does greater exposure to images that perpetuate stereotypes and seek to make viewers feel better about themselves ultimately result in a greater understanding of disability, or dispel stereotypes and myths about people who have disabilities? Does this type of exposure result in "not making it weird"? Not necessarily. For instance, an advertising campaign for a well-known beer portrayed six athletic men competing against each other on a basketball court; all of the players were using wheelchairs to move around the court in what appeared to be a highly competitive game, including a scene where one individual was knocked over in his wheelchair, but pushed to get himself upright and continue with the game. At the end of the commercial, however, five of the six men stood up from their wheelchairs and exited the gym alongside one man using a wheelchair. Then they all went to a bar to have a beer together while the voiceover stated "Dedication. Loyalty. Friendship. The choices we make reveal the true nature of our character." While Taube (2013) lauded this commercial as "aligning its product with a brand of masculinity that has long been absent from beer advertising" (para. 8), other disability advocates, such as Lawrence Carter-Long, have suggested that ads such as the one described above are more about "tokenism" than inclusion. Carter-Long stated,

In the context of "dedication, loyalty, friendship" and ultimately "character," wheelchair basketball in this ad is not positioned as fellowship or camaraderie but rather as something much more paternalistic. The non-disabled guys get to feel good about themselves, but once again, the actual wheelchair user is placed in a supporting role. That's not an accommodation and isn't friendship either-it's tokenism (Davis, 2014, para. 7).

Another example that challenges the belief that greater exposure to media portrayals of people with disabilities as always being positive can be seen in the American reality television series by Bunim/Murray Productions, Born This Way, which features the daily lives of seven young adults who have Down syndrome (Wikipedia, n.d.). While this show certainly depicts the individuals living what appear to be "typical" lives, facing the same types of challenges that their peers without disabilities face, most episodes are shot with only the cast members (i.e. the individuals with disabilities) and their families, making it appear-accurately or not-that they lead segregated lives. Although this is likely not their actual reality, these portrayals may unintentionally perpetuate the belief that people with disabilities prefer to be around only others who have disabilities or, even more concerning, the belief that they should only be with others who have disabilities.

\section{Faltruism}

"Faltruism", a word coined in 2016 by Molly Franks of Bowie, Maryland, an employment professional providing supports to people with disabilities, describes the act of sharing "inspirational" stories about people with disabilities in order to make nondisabled people feel better about themselves: "The belief in or practice of selfless concern for the well-being of others while consciously or subconsciously doing so for the benefit of oneself" (personal communication, 2016). For example, a story ostensibly focused on the success of a person with disabilities may be hijacked by describing how another person, obviously nondisabled, intentionally let the person with disabilities win a competition, or invited the person with a disability to prom. What may 
initially be observed as an opportunity for inclusion is twisted into a celebration of the person without disabilities and their charitable action. Rather than promoting the equality and empowerment of people with disabilities, or even impacting the negative perceptions the public may hold, these stories ultimately reinforce the belief that people with disabilities are objects to be pitied or used to make the nondisabled population feel good (Glynn, Perkins Nerlich, Accordino, 2018).

\section{Is this newsworthy?}

Blog writer Crippled Scholar (2015) provided some insight into determining whether or not a story is newsworthy or just another example inspiration porn:

A good way to gauge whether a story about disability is newsworthy is to ask these two questions:

1. If the subject of this story was replaced by a nondisabled person, would this still be news? If the answer is no, then you may want to reconsider it.

2. Who is the target audience, is it everyone (this includes disabled people) or is it meant to appeal predominantly to nondisabled people? If the latter you should definitely think twice before running with it. If you are unsure, you should consult with disabled people to see how they feel about the story (the plurality of people is really important here). (para. 8)

With an understanding of the concept of faltruism, the phenomenon can be readily identified in media sources and popular culture. In the conversation about whether or not a given portrayal of an event has potential for positive impact on public perceptions of disability versus benefitting those who are not disabled, a new question was raised by the authors: Is this newsworthy? In the first iteration of Stop Making It Weird ${ }^{\mathrm{TM}}$, a viral news story was shared for discussion. On January 26, 2016 The Sun Chronical published a story titled, "Norton High School wrestler no longer undefeated, but still a winner." The story was about two high school students, Andrew Howland, who has Down Syndrome, and Deven Schuko, who does not have a disability. Schuko was celebrated as the hero for allowing Howland to wrestle him and letting him win the match, in spite of Schuko's undefeated record (Foster, 2016). However, by throw- ing the match, Schuko did not allow Howland the dignity of truly showcasing his wrestling skills. Perhaps he would have lost, but perhaps he would have still won. This story does not meet the criteria to be newsworthy. It is a contradiction to advocate for people with disabilities to live typical lives but then also celebrate and perpetuate stories such as this. Disability professionals, and society at large, must challenge prevailing attitudes and assumptions, however wellintentioned they may be, in order to strive for true inclusion.

Another example of inspiration porn masquerading as newsworthiness has been demonstrated by the Night to Shine proms sponsored by the Tim Tebow Foundation. Tebow described the event as "one night where they're all crowned as prom kings and queens.... And we're finding that communities are starting to treat these people different all year around" (Henley, 2018, para. 2). This type of event, although high in notoriety and recognition in media outlets, has been targeted as reminiscent of the "separate but equal" construct historically applied to people of color, by creating "special" events that ultimately increase separation between people who have disabilities and those who do not. In an effort to make people with disabilities feel included in typical activities, events like this end up segregating them instead. To make matters worse, media outlets often respond by celebrating those who create such events, objectifying people with disabilities as inspirations for being able to participate in a regular activity such as prom. When Tebow says, "they're [italics added] all crowned," and, "these [italics added] people," what he's really doing is "othering" people with disabilities putting them in a separate category all their own (Henley, 2018). Alaina Leary, an editor and writer who lives with autism and Ehlers-Danlos syndrome said, "Inclusion and acceptance means that the disability community is a part of everything that non-disabled people are doing, and that the events planned are fully accessible for everyone and there's no need, then, to create a disability-specific event" (Henley, 2018, para. 12),

In contrast, a news article published online by ABC News writer Andrea Miller (November 27, 2017) shared the story of Mikayla Holmgren, the first woman with Down syndrome to compete in the Miss USA state pageant in Minnesota. Rather than focusing solely on her accomplishment because she is a person with a disability, the story highlighted the historical significance of the fact that Holmgren was the 
first person with Down syndrome to compete in the pageant. The article went on to describe that history also had been made the previous year when the first Somali-American woman wearing a hijab had participated in the Miss Minnesota USA pageant. This portrayal respectfully described the accomplishment without cheapening the experience. This is newsworthy.

\section{Perspectives on "Weirdness"}

A panel of individuals who have disabilities participated in this session and were asked to share their perspectives on several of the topics presented throughout the session. Their responses provide a richer context to \#stopmakingitweird and are summarized below.

A. Tell us about a time when you experienced someone "making it weird" by celebrating you for completing an ordinary task or calling you an inspiration for accomplishing something that's rather ordinary.

i. Panelist 1:

When you compete in [Special Olympics], you always get to "win" a medal or ribbon and no one loses. I guess that is to make it fun for all. ... One time, I was in a walking race and $\mathrm{I}$, by mistake, lifted my heel and one of the judges at the competition disqualified me. So that is fine because I did violate that rule about walking and so I was ok with that decision. But then another official at the race saw that this happened to me and I might have looked a bit upset, because I like to compete and win!! So, this person came running over and made a fuss and ended up having the race coordinators give me a GOLD medal... !! I was a bit stunned and confused. I took the medal and went off to lunch. But as I was processing everything at lunch, I said to myself, "WHAT THE HECK, I don't deserve nor did I win a Gold medal, I disqualified myself by lifting my heel.” So I went back to the judges and coordinators and I gave them their gold medal back. Then I was happy and that judge who gave me the gold medal should have understood that I am playing by the rules and I won't die if I don't win Gold! That is respecting me. (T. Egan, personal communication, June 26, 2018)

ii. Panelist 2:

I get, "You can drive that chair good," or, "You can sure type good on that iPad with your head stick." To me it's just how I do things but to other people it's amazing, which doesn't bother me. I feel anytime that a non-disabled person interacts with a person with a disability in a positive manner it's a good thing. When I first moved in my neighborhood and people would see me out and about they would say, "You are an inspiration," which really doesn't bother me either, I just say, "Thanks," and go about my business. Maybe the next time I see that person we will have a conversation. Again there's that interaction with a person with a disability that I feel is so critical to change the perception of people. Instead of getting insulted or mad about someone calling me an inspiration, I try to show them just because I have a disability I'm no different than anybody else (K. Capone, personal communication, June 26, 2018).

B. Tell us about a time when you experienced someone "not making it weird" by treating you like they would any other person.

i. Panelist 1:

[One] example is theater and acting-I think that stereotypes and old thinking makes people not respect a person with disability as an equal to them. But, every time I have been in a play, the cast gets to know me as a person and there are no stereotypes. Then the audience sees me in a role in the play and they cannot see a "special" person but instead they see an actor! (T. Egan, personal communication, June 26, 2018).

ii. Panelist 2:

I go to the horse track sometimes; I've met a lot of people there from the tellers to the people who put the horses in the gate to the people who are there just like me who are betting. They don't treat me any different because I am a person with a disability. We celebrate when someone wins and we mess with someone who lost (K. Capone, personal communication, June 26, 2018). 


\section{Recommendations: Stop making it weird}

The conference panelists were asked, "What recommendations do you have for people who would like to 'stop making it weird'? How do you prefer to be treated by others?" Their responses provide meaningful insights from people who experience disabilities.

A. Panelist 1:

When I was [completing my internship] at Project SEARCH, I had to build my confidence to knock on doors and go into patient rooms. I was shy at first but when I realized that the patients were respecting me and appreciating my work, I felt even more confidence.... . If you will look into my eyes, LISTEN to ME ... even if I need more time than you to talk, if you listen, the truth will be apparent. We all have abilities and disabilities (T. Egan, personal communication, June 26, 2018).

B. Panelist 2:

It's simple; just treat people as you want to be treated. I am not looking for any special treatments or to be treated any different from the general public. I want to be seen as an adult male [who] is employed, [who] is a homeowner and [who] likes companionship. I want to see an inclusive world where we see one's ability, not their disability. I want people to smile and start up a conversation with me. We are all human beings, just because I use a wheelchair and assistive technology doesn't make me any different. I believe that whether you were born with a disability or without we truly want the same thing. That is to be employed, contributing citizens, homeowners, and to have relationships and families (K. Capone, personal communication, June 26, 2018).

One of the keys to Stop Making It Weird ${ }^{\mathrm{TM}}$ is to engage in conversations that matter. A truly meaningful dialogue about how disability professionals and our greater society continue to create barriers to equality, empowerment and true inclusion for people with disabilities must include people with disabilities. Look into people's eyes when you speak to them. Ask questions when you need clarification. Listen to people's stories and seek understanding without looking for personal benefit. Offer support if it is requested and treat people as you want to be treated. Join the \#stopmakingitweird movement. Take the pledge to \#stopmakingitweird by going to www.stopmakingitweird.com, and join us in sharing and continuing the conversation on Facebook at www.facebook.com/stopmakingitweird and by using the Twitter handle @STPMKNGITWRD.

\section{Conflict of interest}

None to report.

\section{References}

Crippled Scholar. (2015). A media guide for nondisabled people talking about innovations for disabled people [Web log comment]. Retrieved from https://crippledscholar. com/2015/08/06/a-media-guide-for-nondisabled-peopletalking-about-innovations-for-disabled-people/

Davis, C. J., \& Thibedeau Boyd, J. M. (2017). Stop making it weird: Why I'm not clapping. Journal of Vocational Rehabilitation, 46, 321-325.

Davis, D. (2014). Disability as “inspiration:" Can greater exposureovercome this phenomenon? Retrieved from https://pushliving.com/disability-as-inspiration-can-greaterexposure-overcome-this-phenomenon/

Foster, R. (2016). Norton High School wrestler no longer undefeated, but still a winner [Electronic version]. The Sun Chronicle. Retrieved from http://www.thesunchronicle.com/ news/local news/norton-high-school-wrestler-no-longer-unde feated-but-still-a/article 2ce2861b-f56e-512c-b4c0-15af7bf57 a33.html

Glynn, K. M., Perkins Nerlich, A., \& Accordino, M. P. (2018). Public perceptions of disability. In A. Perkins Nerlich \& K. M. Glynn (Eds.), Psychology of disability (2nd ed.). Aspen Professional Services.

Henley, A. (2018). We don't need events specifically for disabled people. Retrieved from https://tonic.vice.com/en_us/article/ $7 \times 7 \mathrm{myx} /$ prom-for-disabled-people-perpetuates-stigma?utm source=tonicfbus

Miller, A. (2017). Woman with Down syndrome is 1st to compete in Miss USA state pageant [Electronic version]. Retrieved from https://abcnews.go.com/US/woman-syndrome-1stcompete-miss-usa-state-pageant/story?id=51407987

Taube, A. (2013). An incredible new Guinness ad breaks the industry stereotype. Business Insider. Retrieved from https://www.businessinsider.com/new-guinness-ad-breaksthe-mold-2013-9

Wikipedia. (n.d.) Born This Way (TV Series). Retrieved from https://en.wikipedia.org/wiki/Born_This_Way_(TV_series)

Young, S. (2014). I'm not your inspiration, thank you very much [Video file]. Retrieved from https://www.ted.com/talks/ stella_young_i_m_not_your_inspiration_thank_you_very_much 